University of New Hampshire

University of New Hampshire Scholars' Repository

$9-1-1990$

\title{
Involvement of cyclic AMP in multiple, excitatory actions of biogenic amines on the cardiac ganglion of the horseshoe crab Limulus polyphemus
}

Winsor H. Watson III

University of New Hampshire, Durham, win.watson@unh.edu

J. R. Groome

University of New Hampshire, Durham

Follow this and additional works at: https://scholars.unh.edu/jel

\section{Recommended Citation}

Groome, J. R. and W. H. Watson III. 1990. Involvement of Cyclic AMP in multiple, excitatory actions of biogenic amines on the cardiac ganglion of the horseshoe crab Limulus polyphemus J. Exp. Biol. 152: 313-331. http://jeb.biologists.org/content/jexbio/152/1/313.full.pdf

This Article is brought to you for free and open access by the Institute for the Study of Earth, Oceans, and Space (EOS) at University of New Hampshire Scholars' Repository. It has been accepted for inclusion in Jackson Estuarine Laboratory by an authorized administrator of University of New Hampshire Scholars' Repository. For more information, please contact Scholarly.Communication@unh.edu. 


\title{
INVOLVEMENT OF CYCLIC AMP IN MULTIPLE, EXCITATORY ACTIONS OF BIOGENIC AMINES ON THE CARDIAC GANGLION OF THE HORSESHOE CRAB LIMULUS POLYPHEMUS
}

\author{
BY JAMES R. GROOME* AND WINSOR H. WATSON III \\ Department of Zoology, University of New Hampshire, Durham, \\ NH 03824, USA
}

Accepted 4 April 1990

\begin{abstract}
Summary
Cyclic AMP appears to be involved in several excitatory actions of amines on neurones of the Limulus cardiac ganglion. Amines selectively increase levels of cardiac ganglion cyclic AMP with a magnitude and time course similar to that observed for amine-induced excitation of cardiac ganglion burst rate. With respect to either the physiological or biochemical effect, the apparent order of potency is octopamine $>$ epinephrine $\approx$ dopamine $>$ norepinephrine. Elevation of cardiac ganglion cyclic AMP levels by octopamine or dopamine is dose-dependent and is potentiated by the phosphodiesterase inhibitor 3-isobutyl 1-methylxanthine (IBMX).

Several pharmacological agents which influence cyclic nucleotide metabolism, including forskolin, IBMX and 8-substituted cyclic AMP analogues, have aminelike effects on the Limulus cardiac ganglion. These effects include increased burst rate of the isolated cardiac ganglion and decreased burst duration, interburst interval and number of spikes per burst in follower neurones. Forskolin and IBMX increase levels of cardiac ganglion cyclic AMP, and IBMX also increases cyclic GMP levels in this tissue.

Amines, forskolin and IBMX have direct effects on follower neurones pharmacologically isolated from pacemaker cell input. Octopamine, forskolin and IBMX depolarize follower neurones, while dopamine hyperpolarizes these cells. Amines, forskolin and IBMX elicit burst-like potentials in follower neurones, and increase the size of evoked, unitary junction potentials recorded in cardiac muscle fibres. These pharmacological and biochemical data suggest that multiple, excitatory effects of biogenic amines on the Limulus cardiac ganglion are mediated by simultaneous increases in cyclic AMP at several loci within this neural network.
\end{abstract}

* Present address: Department of Biology, Utah State University, Logan, UT 84322-5305, USA.

Key words: cyclic AMP, amines, cardiac ganglion. 


\section{Introduction}

The heartbeat of the horseshoe crab, Limulus polyphemus, was shown to be neurogenic in origin by Carlson in 1904. In the Limulus cardiac ganglion, small (20-40 $\mu \mathrm{m}$ diameter) bipolar or multipolar pacemaker cells control the heart rate (Lang, 1971). These neurones exhibit a slowly decaying potential which gives rise to a single overshooting action potential at the onset of the heartbeat. The pacemaker neurones apparently synapse with larger (60-150 $\mu \mathrm{m}$ diameter) follower cells and initiate bursts of action potentials in these motor neurones, which drive rhythmic contractions of the myocardium (Palese et al. 1970). The cardiac rhythm is modulated by several biogenic amines, including octopamine (OCT), dopamine (DA), epinephrine (EPI) and norepinephrine (NE). These amines act on multiple cellular targets within this system to produce long-lasting increases in the rate and strength of heart contractions (reviewed by Watson and Augustine, 1982; Watson and Groome, 1989). The characterization of these effects, combined with the detection of OCT and the catecholamines in the Limulus central nervous system and cardiac ganglion (Edwards et al. 1979; O'Connor et al. 1982) suggest that these amines may have an important cardioregulatory role in horseshoe crabs, as may be true in other arthropods (reviewed by Cooke and Sullivan, 1982; Benson, 1984).

The excitatory chronotropic effects of OCT and the catecholamines on the Limulus heartbeat are the result of their actions on the cardiac ganglion (Augustine et al. 1982). Amines increase the burst frequency of the isolated cardiac ganglion by increasing the firing rate of pacemaker neurones (Augustine and Fetterer, 1985). Increased burst rate is accompanied by multiple changes in follower neurone activity. These changes include a decrease in burst duration and a reduction in the number of action potentials per burst. Amines also directly depolarize (OCT, EPI) or hyperpolarize (DA, NE) follower neurones. While the sites of action of these amines on the Limulus cardiac ganglion have been investigated in some detail, the intracellular events underlying amine modulation have not been determined.

Cyclic AMP appears to be an important second messenger in the chronotropic action of amines on the neurogenic hearts of crustaceans and Limulus. Octopamine increases the cyclic AMP level and beat frequency of the hearts of the crab Cancer (Sullivan and Barker, 1975) and the lobster Homarus (Battelle and Kravitz, 1978). In Limulus, OCT and DA increase levels of cyclic AMP in the cardiac ganglion, and pharmacological elevation of cyclic AMP level increases heart rate (Groome and Watson, 1987). The alpha-adrenergic antagonist phentolamine blocks amine-induced chronotropic excitation (Augustine et al. 1982) as well as increases in cardiac ganglion cyclic AMP produced by OCT or DA (Groome and Watson, 1987). However, no study to date has demonstrated a role for cyclic AMP as a second messenger underlying specific actions of amines on the arthropod cardiac ganglion.

Amines enhance heart contraction strength in Limulus by increasing the contractility of cardiac muscle fibres (postsynaptic action; Watson et al. 1985) and 
by increasing transmitter release from follower neurones (presynaptic action; Watson and Hoshi, 1981; Watson et al. 1985). While it has been shown that changes in Limulus cardiac muscle contractility involve cyclic AMP as a second messenger (Groome and Watson, 1989), the mechanisms underlying amine modulation of transmitter release by the follower neurones are not known. However, the involvement of second messengers in this effect has been suggested by the time course of the amine-induced increases in evoked cardiac muscle junction potentials (Watson et al. 1985).

In this paper, a combination of pharmacological and biochemical data are presented which suggest that cyclic AMP is involved in several actions of OCT and catecholamines on the Limulus cardiac ganglion. Amines increase the burst rate of the Limulus cardiac ganglion via a cyclic-AMP-dependent mechanism. Cyclic AMP appears to be involved in the depolarizing action of octopamine on Limulus follower neurones as well as amine-induced enhancement of cardiac neuromuscular transmission. These results suggest that a common second messenger, cyclic AMP, is involved in excitatory chronotropic and inotropic actions of amines at multiple sites within the Limulus cardiac ganglion.

\section{Materials and methods}

\section{Animals}

Horseshoe crabs (Limulus polyphemus) were purchased from the supply department of the Marine Biological Laboratories at Woods Hole, Massachussets, or collected from Great Bay, New Hampshire. Horseshoe crabs were maintained on a diet of mussels (Mytilus edulis) in flow-through sea tables located at the Jackson Estuarine Laboratories, University of New Hampshire. Horseshoe crabs with a carapace width of $15-25 \mathrm{~cm}$ were used in this study. Typically, larger animals were used in experiments on cardiac ganglia, while smaller animals were utilized for experiments on the cardiac neuromuscular junction.

\section{Cyclic nucleotide assay}

Cardiac ganglia were isolated from freshly dissected Limulus hearts by teasing the ganglion away from the underlying myocardium and severing the motor roots. Isolated ganglia were transferred to glass vials containing $5 \mathrm{ml}$ of natural sea water (obtained from Portsmouth Harbor, $\mathrm{NH}$ ). In all experiments, cardiac ganglia were incubated for $60 \mathrm{~min}$ in sea water at room temperature $\left(20-23^{\circ} \mathrm{C}\right)$, and tests were then initiated by adding $5 \mathrm{ml}$ of drug solutions to each vial. Incubations were terminated by immersing the tissue in $1 \mathrm{ml}$ of ice-cold $6 \%$ trichloroacetic acid, followed by homogenization. The extraction and radioimmunoassay (RIA) protocols for cyclic AMP and cyclic GMP have been described previously (Groome and Watson, 1987). Cyclic AMP and cyclic GMP standards (Sigma Chemical Co., Saint Louis, MO) were prepared from frozen stock solutions. Levels of cyclic nucleotides were normalized by measuring cardiac ganglion frotein content (Lowry et al. 1951). 


\section{Recordings}

Isolated cardiac ganglia were pinned to Sylgard resin in the bottom of $5 \mathrm{ml}$ acrylic chambers and continuously perfused $\left(5 \mathrm{ml} \mathrm{min}^{-1}\right)$ with sea water at room temperature. Suction electrodes were used to record extracellular potentials from cardiac ganglia, and these were displayed on an oscillograph (Brush 220, Gould Inc., Cleveland, $\mathrm{OH}$ ).

Follower neurones within Limulus cardiac ganglia were impaled with glass microelectrodes $\left(3 \mathrm{moll}^{-1} \mathrm{KCl}, 25-40 \mathrm{M} \Omega\right.$ resistance). Membrane potentials were monitored with a high-impedance input preamplifier (Dagan 8700, Dagan Corp., Minneapolis, MI) and displayed on an oscillograph.

To examine cardiac neuromuscular transmission, $2-3 \mathrm{~cm}$ sections of deganglionated Limulus hearts were opened with a mid-ventral incision and pinned, dorsal side up, to the bottom of $5 \mathrm{ml}$ perfusion chambers. Flow rate was adjusted to approximately $3 \mathrm{ml} \mathrm{min}^{-1}$. The membrane potentials of cardiac muscle fibres were recorded as described for follower neurones. Suction electrodes were used to stimulate residual motor nerves and elicit excitatory junction potentials (EJPs) in these muscle fibres. Stimulation parameters were adjusted $(0.1-0.4 \mathrm{~V}, 2-6 \mathrm{~ms})$ to obtain unitary EJPs. Successive EJPs were averaged ( 30 sweeps at 0.5 pulses s $^{-1}$ ) and stored at $5 \mathrm{~min}$ intervals using a digital oscilloscope (Nicolet Biomedical Instr., Madison, WI). Apparent input resistances of follower neurones or cardiac muscle fibres were measured by injecting hyperpolarizing current pulses $(0.1-0.3 \mathrm{nA}$, $10-20 \mathrm{~ms})$.

\section{Solutions}

Solutions were prepared in natural sea water from a concentrated stock solution or from powder. The vehicles used to dissolve drugs $(95 \%$ ethanol for forskolin, $0.1 \mathrm{moll}^{-1}$ acetic acid for amines, dimethyl sulphoxide for R0-20-1724) had no overt effect on any preparations at the dilutions employed. Drugs were obtained from the following sources: DL-epinephrine (EPI, Sigma), ( \pm )arterenol (DL-norepinephrine, NE, Sigma), 3-hydroxytyramine hydrochloride (dopamine, DA, Sigma), 3-isobutyl 1-methylxanthine (IBMX, Sigma), DL-octopamine (OCT, Sigma), forskolin (Calbiochem Biochemicals, San Diego, CA), R0-20-1724 (a gift from Hoffman LaRoche, Nutley, NJ), 8-parachloro-phenylthio cyclic AMP (8-pcpt cAMP), and 8-benzylthio cyclic AMP (8-bt cAMP, ICN Pharmaceuticals, Irvine, CA). Test solutions were added via the perfusion reservoir.

\section{Results}

Effects of amines on burst rate and cyclic nucleotide levels

At $10^{-5} \mathrm{moll}^{-1}$, OCT, DA, EPI and NE all increased the burst rate of isolated cardiac ganglia (Table 1; Fig. 1). The apparent order of potency for this effect was OCT $>$ DA $\approx$ EPI $>$ NE. All four amines tested, at $10^{-5} \mathrm{moll}^{-1}$, also increased cyclic AMP levels in Limulus cardiac ganglia with no effect on levels of cyclic GMP (Table 1, Figs 1, 2). The apparent order of potency for amine-induced accumu 
Táble 1. Chronotropic and biochemical effects of amines and pharmacological agents on Limulus cardiac ganglia

\begin{tabular}{lcccc}
\hline Agent & $\begin{array}{c}\text { Dose } \\
\left(\mathrm{mol} \mathrm{l}^{-1}\right)\end{array}$ & $\begin{array}{c}\text { \% Control } \\
\text { burst rate }\end{array}$ & $\begin{array}{c}\text { pmol cyclic AMP } \\
(\% \text { control })\end{array}$ & $\begin{array}{c}\text { pmol cyclic GMP } \\
(\% \text { control })\end{array}$ \\
\hline Control & & 100 & $26.2 \pm 8.2,100(10)$ & $5.7 \pm 0.9,100(10)$ \\
Amines & & & & \\
OCT & $10^{-5}$ & $246.8 \pm 15.9(12) \dagger$ & $104.5 \pm 26.2,398.9(10) \dagger$ & $4.1 \pm 0.3,71.9(6)$ \\
EPI & $10^{-5}$ & $225.2 \pm 48.3(17) \dagger$ & $81.2 \pm 15.6,309.9(8)^{*}$ & $7.3 \pm 0.8,128.0(5)$ \\
DA & $10^{-5}$ & $216.8 \pm 14.4(14) \dagger$ & $66.9 \pm 13.5,255.3(10)^{*}$ & $5.2 \pm 0.791 .2(6)$ \\
NE & $10^{-5}$ & $166.1 \pm 7.2(20)^{*}$ & $42.6 \pm 8.9,162.6(8)$ & $6.6 \pm 0.8,115.8(5)$ \\
Pharmacological agents & & & \\
Forskolin & $5 \times 10^{-6}$ & $225.0 \pm 11.3(12) \dagger$ & $65.8 \pm 11.9,251.1(8)^{*}$ & $4.2 \pm 0.7,73.7(6)$ \\
IBMX & $10^{-3}$ & $201.4 \pm 10.6(15) \dagger$ & $55.3 \pm 10.4,211.1(8)^{*}$ & $73.7 \pm 19.0,1293.0(6) \dagger$ \\
RO-20-1724 & $10^{-3}$ & $118.0 \pm 7.6(8)$ & $21.6 \pm 7.8,82.4(9)$ & ND \\
8-bt cAMP & $10^{-3}$ & $149.7 \pm 9.7(6)^{*}$ & ND & ND \\
8-pcpt cAMP & $10^{-3}$ & $133.9 \pm 7.7(8)^{*}$ & ND & ND
\end{tabular}

All values represent the mean \pm S.E.M. in $(N)$ experiments.

Measurements of rate changes indicate the peak physiological effect, while biochemical values were obtained after $10 \mathrm{~min}$ of incubation.

Determinations of significant difference from controls were obtained using a Student's $t$-test on absolute values.

Level of significance: $\dagger(P \leqslant 0.02) ;{ }^{*}(P \leqslant 0.05)$.

OCT, octopamine; EPI, epinephrine; DA, dopamine; NE, norepinephrine.

lation of cyclic AMP in this tissue was identical to that observed for elevation of cardiac ganglion burst rate.

To examine the time course of these effects, cardiac ganglia were exposed to $10^{-5} \mathrm{moll}^{-1} \mathrm{OCT}$ or $10^{-5} \mathrm{moll}^{-1} \mathrm{DA}$ for periods ranging from $30 \mathrm{~s}$ to $10 \mathrm{~min}$, and in some experiments subsequently washed in amine-free sea water. The onset of the increase in cardiac ganglion cyclic AMP level produced by either OCT or DA was similar in time course to their effect on burst rate (Fig. 1). However, while cyclic AMP levels returned to control values within 5-10 min after removal of amine, cardiac ganglion burst rate declined more slowly to control values over the course of $60 \mathrm{~min}$. Continued presence of amine in the incubation solution (15-20 min) resulted in a continued elevation of cardiac ganglion cyclic AMP level and burst rate (data not shown). Cardiac ganglion cyclic GMP levels were not increased by $10^{-5} \mathrm{moll}^{-1} \mathrm{OCT}$ or $10^{-5} \mathrm{moll}^{-1} \mathrm{DA}$ in any period $(30 \mathrm{~s}, 1,2,3,5$ or $10 \mathrm{~min} ; N=5-6$ for each time point).

Cardiac ganglion cyclic AMP levels were increased by OCT and DA in a dosedependent manner (Fig. 2A). After $3 \mathrm{~min}$ of incubation, the threshold dose for either DA or OCT was approximately $3 \times 10^{-6} \mathrm{moll}^{-1}$. At all doses tested $\left(10^{-6} \mathrm{moll}^{-1}\right.$ to $\left.5 \times 10^{-5} \mathrm{moll}^{-1}\right)$, neither of these amines increased levels of Cardiac ganglion cyclic GMP (Fig. 2B). 

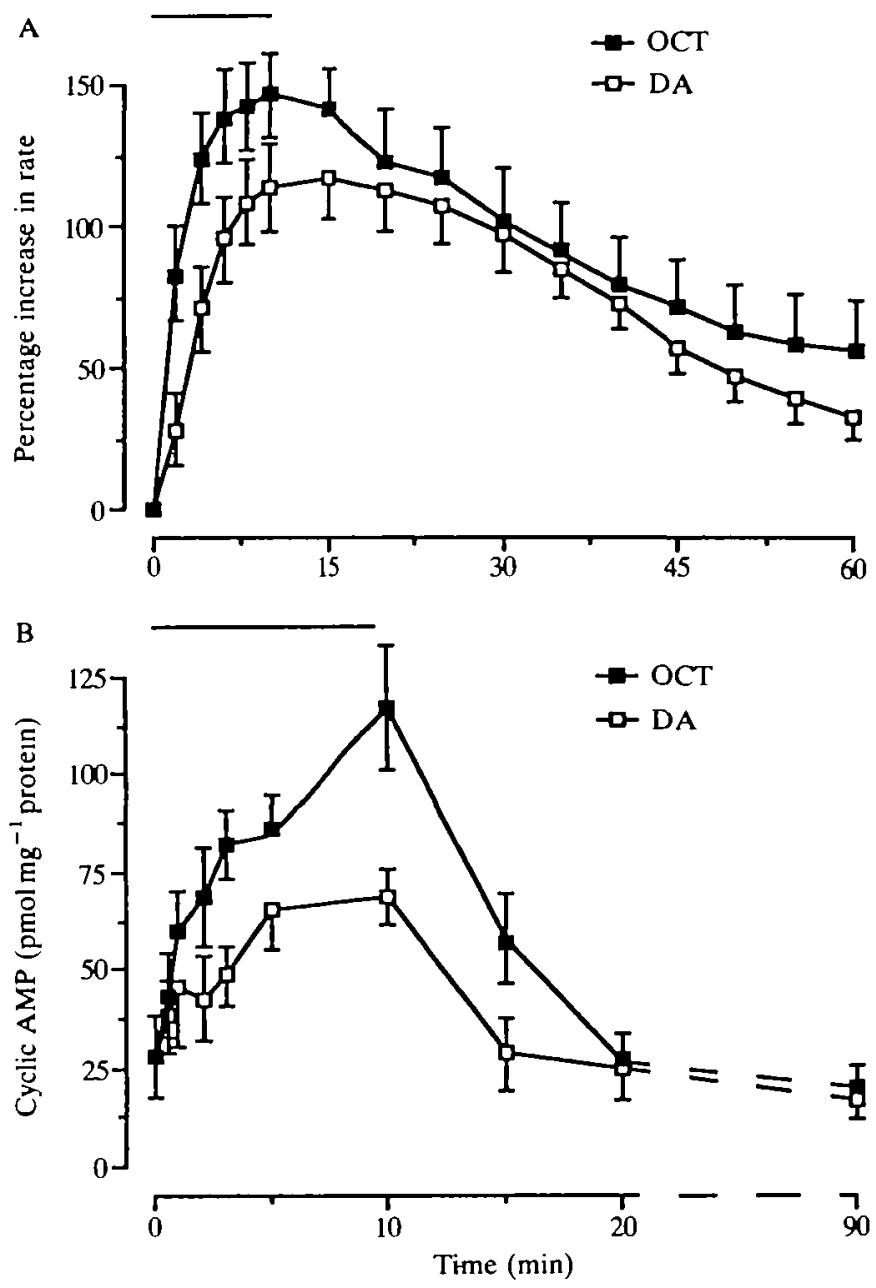

Fig. 1. Amines produced long-lasting increases in the burst rate and cyclic AMP content of isolated cardiac ganglia. (A) Octopamine (OCT, $10^{-5} \mathrm{~mol}^{-1}$ ) or dopamine (DA, $10^{-5} \mathrm{moll}^{-1}$ ) were added to isolated ganglia for $10 \mathrm{~min}$ (solid line) and subsequently removed from the bath. Each point represents the mean increase in rate ( \pm s.E.M.) recorded in 12-14 preparations. (B) Onset and washout kinetics of amineinduced elevation of cardiac ganglion cyclic AMP content. Cardiac ganglia were immersed in $10^{-5} \mathrm{moll}^{-1}$ OCT or $10^{-5} \mathrm{moll}^{-1}$ DA for $30 \mathrm{~s}$ to $10 \mathrm{~min}$ (solid line). Ganglia were then processed for determination of cyclic AMP content, or washed in amine-free sea water for 5-80 $\mathrm{min}$ and then processed. Each point represents the mean content of cardiac ganglion cyclic AMP ( \pm s.E.M.) in 6-8 experiments. Note that the $x$ axis (time) differs in $\mathrm{A}$ and $\mathrm{B}$.

Effects of pharmacological agents on burst rate and cyclic nucleotide levels

Forskolin, an activator of adenylate cyclase (Seamon and Daly, 1981), at $5 \times 10^{-6} \mathrm{moll}^{-1}$, or IBMX, a phosphodiesterase inhibitor (Evans, 1984a), $10^{-3} \mathrm{moll}^{-1}$, significantly increased the burst rate of Limulus cardiac ganglia 

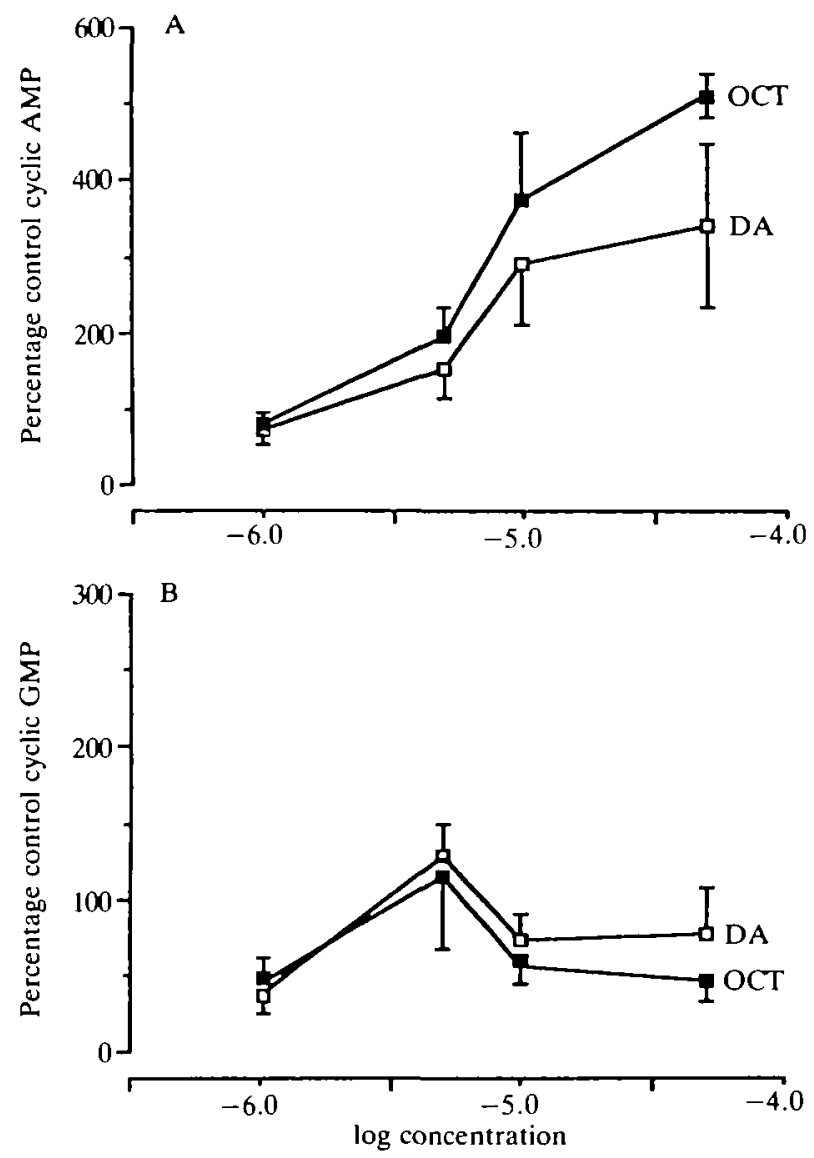

Fig. 2. Octopamine and dopamine produced dose-dependent increases in levels of cardiac ganglion cyclic AMP (A), but not of cyclic GMP (B). Each point represents the mean (IS.E.M.) of five experiments in which individual cardiac ganglia were exposed to a particular dose of amine for $3 \mathrm{~min}$. At this time, the threshold dose for the effect of either amine to increase cardiac ganglion cyclic AMP level was between $10^{-6}$ and $3 \times 10^{-6} \mathrm{moll}^{-1}$.

(Table 1; Fig. 3). The onset of the chronotropic effect produced by IBMX occurred slightly earlier, but was not as large in magnitude as that elicited by forskolin. Both agents, like the amines, produced long-lasting increases in burst rate.

Cyclic AMP levels in cardiac ganglia were increased by forskolin and IBMX at the same doses used for pharmacological experiments (Table 1). Like its effect on burst rate, the increase in cyclic AMP level produced by IBMX was more rapid in onset than that produced by forskolin. After $3 \mathrm{~min}$, cyclic AMP content was not significantly increased by forskolin $(N=6)$, while IBMX levels had increased by $62.5 \pm 11.4 \%(N=6, P \leqslant 0.05)$. Cyclic GMP levels were unaltered by forskolin, but were significantly increased by IBMX within $3 \mathrm{~min}(1431.5 \pm 313.6 \%$ increase, 

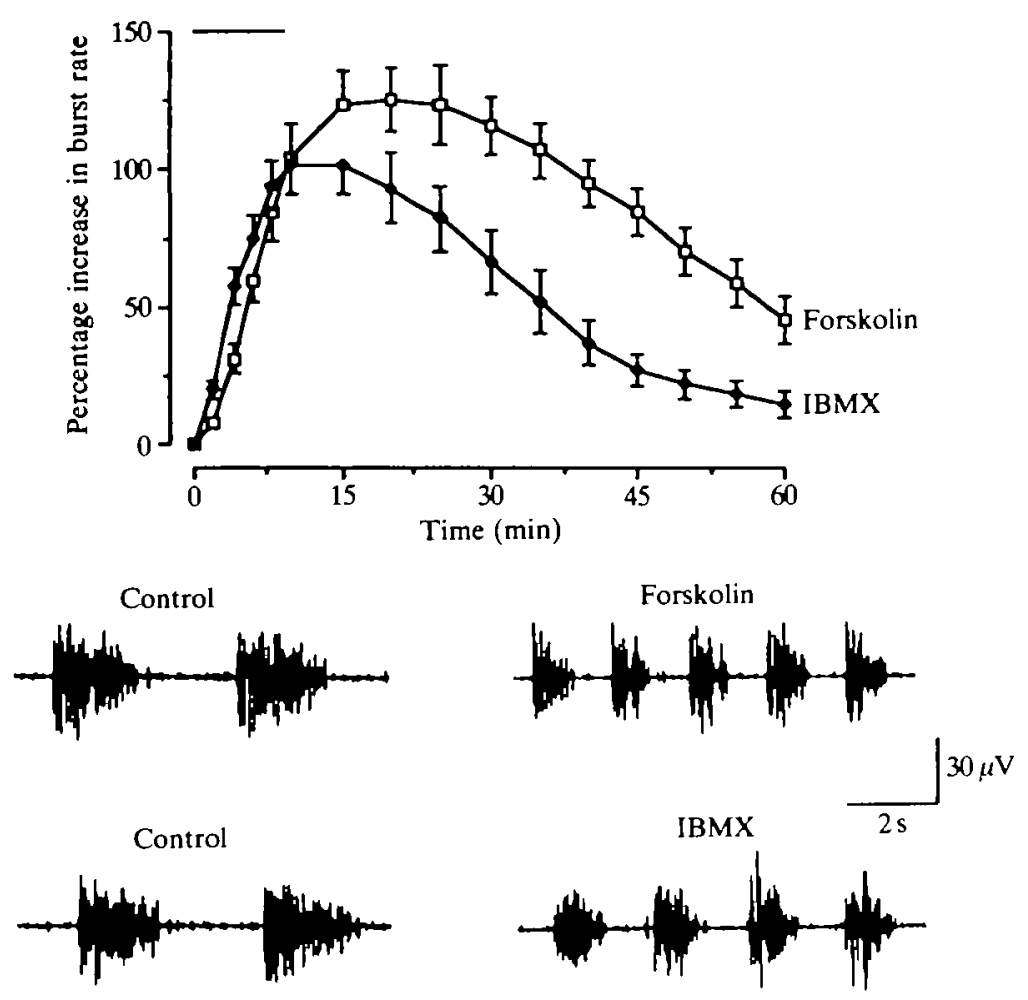

Fig. 3. Forskolin $\left(5 \times 10^{-6} \mathrm{moll}^{-1}\right)$ or IBMX $\left(10^{-3} \mathrm{moll}^{-1}\right)$ increased the burst frequency of isolated Limulus cardiac ganglia. Drugs were added to the preparation for $10 \mathrm{~min}$, as indicated by the solid line (top). Each point represents the mean increase in cardiac ganglion burst rate ( \pm S.E.M.) in $12-16$ experiments. Bottom: extracellular recordings of cardiac ganglion output before addition of agent to the preparation and during the peak response.

$N=6, P \leqslant 0.01)$. Another phosphodiesterase inhibitor, RO-20-1724 $\left(10^{-3} \mathrm{moll}^{-1}\right)$ had little effect on either cardiac ganglion burst rate or cyclic AMP content (Table 1).

The relative capacity of all four amines, forskolin and IBMX to increase cardiac ganglion burst rate was closely correlated $(r=0.94)$ with their capacity to increase levels of cardiac ganglion cyclic AMP. This relationship suggests that cyclic AMP is the primary, if not the sole, second messenger underlying the excitatory chronotropic effect of amines on the Limulus cardiac ganglion.

\section{Potentiation of amine-induced cyclic AMP accumulation by IBMX}

Amine-induced increases in cardiac ganglion cyclic AMP level were potentiated in the presence of IBMX. At $10^{-4} \mathrm{~mol}^{-1}$, IBMX itself had no significant effect on levels of cardiac ganglion cyclic AMP after $3 \mathrm{~min}$ of incubation $(24.9 \pm 6.2 \mathrm{pmol}$, $N=6)$. Neither $10^{-6} \mathrm{moll}^{-1}$ OCT $(20.1 \pm 3.7 \mathrm{pmol}, N=5)$ nor $10^{-6} \mathrm{moll}^{-1} \mathrm{DA}$ $(18.1 \pm 6.6 \mathrm{pmol}, N=5)$ produced significant increases in cyclic AMP at this time. 
However, when $10^{-4} \mathrm{moll}^{-1}$ IBMX was combined with $10^{-6} \mathrm{moll}^{-1}$ amine, significant increases in cyclic AMP were produced by OCT/IBMX $(32.3 \pm 4.0 \mathrm{pmol}, N=4, P \leqslant 0.05)$ and DA/IBMX $(36.8 \pm 4.4 \mathrm{pmol}, N=4, P \leqslant 0.03)$ after the same period.

\section{Effect of amines and pharmacological agents on follower cell activity}

Forskolin $\left(5 \times 10^{-6} \mathrm{moll}^{-1}\right)$ and IBMX $\left(10^{-3} \mathrm{moll}^{-1}\right)$ produced a number of amine-like effects on follower neurone burst parameters (Fig. 4). These agents increased burst frequency and decreased the interval between successive bursts. Additionally, they shortened the duration of the plateau potential during each burst and decreased the number of action potentials fired per burst. These changes in burst characteristics were long-lasting, and their time courses were virtually identical to those of the effects of forskolin and IBMX on cardiac ganglion burst rate.

Cyclic nucleotide analogues also elicited amine-like alterations of cardiac
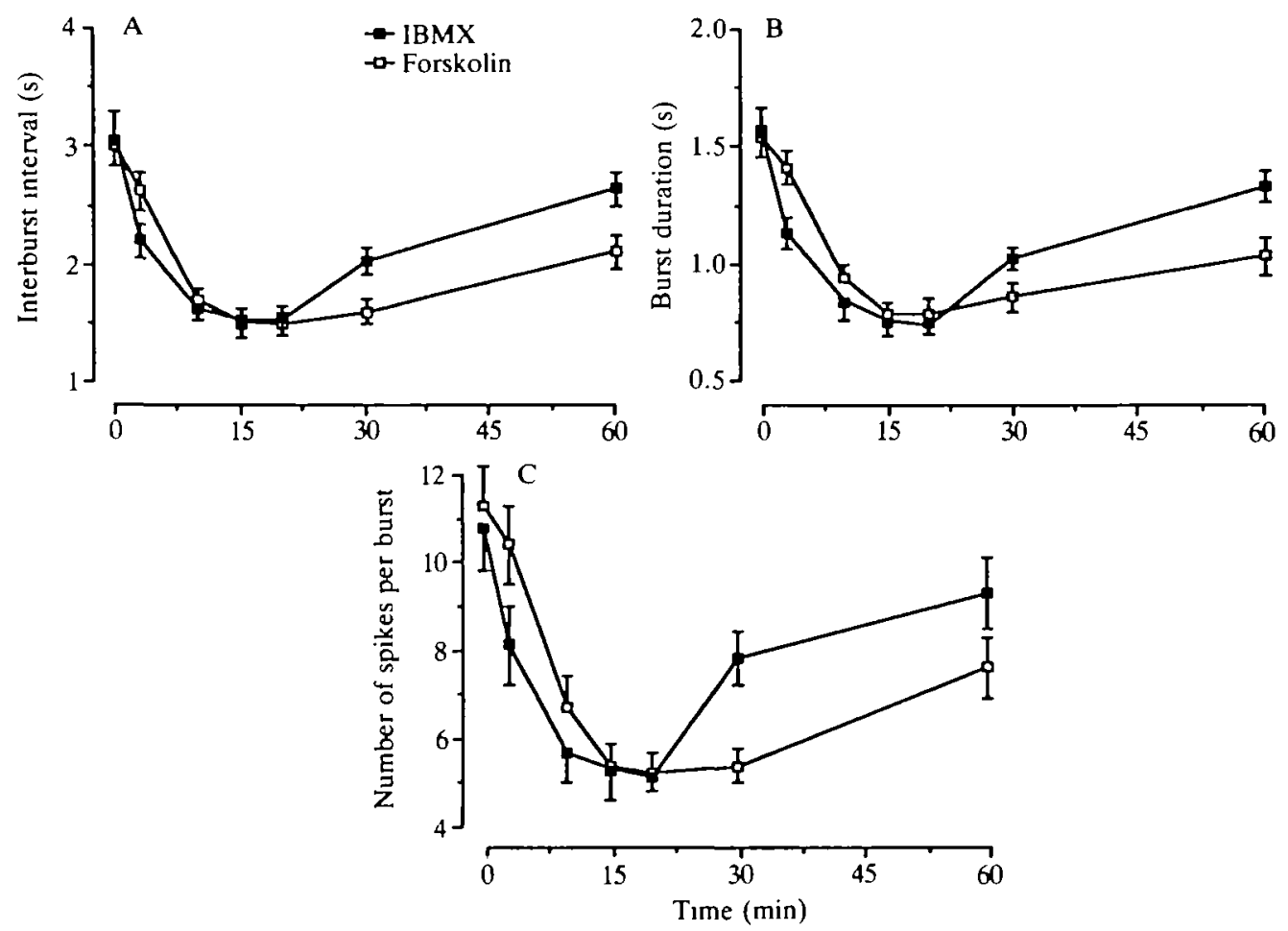

Fig. 4. Time course of alterations in follower cell burst characteristics in cardiac ganglia exposed to $5 \times 10^{-6} \mathrm{moll}^{-1}$ forskolin or $10^{-3} \mathrm{moll} \mathrm{I}^{-1}$ IBMX for $10 \mathrm{~min}$. Interburst interval (A), burst plateau duration (B) and number of action potentials recorded per burst $(C)$ all declined after application of forskolin or IBMX. Each point represents the mean value ( \pm S.E.M.) of 10-14 experiments. 
ganglion burst rate and follower neurone activity (Fig. 5; Table 1). At $10^{-3} \mathrm{moll}^{-1}$, both 8-bt cAMP $(N=6)$ and 8-pcpt cAMP $(N=8)$ produced longlasting effects which were smaller in magnitude, but similar, to those observed during the application of amines, forskolin or IBMX.

\section{Direct effects of forskolin and IBMX on follower neurones}

Follower neurones were pharmacologically isolated from pacemaker neurone input with the introduction of $30 \mathrm{mmoll}^{-1} \mathrm{Mn}^{2+}$ or $30-40 \mathrm{mmoll}^{-1} \mathrm{Co}^{2+}$ to the bath. Manganese transiently hyperpolarized follower neurones by $5-10 \mathrm{mV}$, then depolarized the cells by $15-20 \mathrm{mV}$. Follower cell bursts were progressively lengthened for several minutes, followed by a reversible elimination of most of the spontaneous activity in the cardiac ganglion. Cobalt depolarized follower neurones by $20 \mathrm{mV}$ or more and was used in only a few experiments.
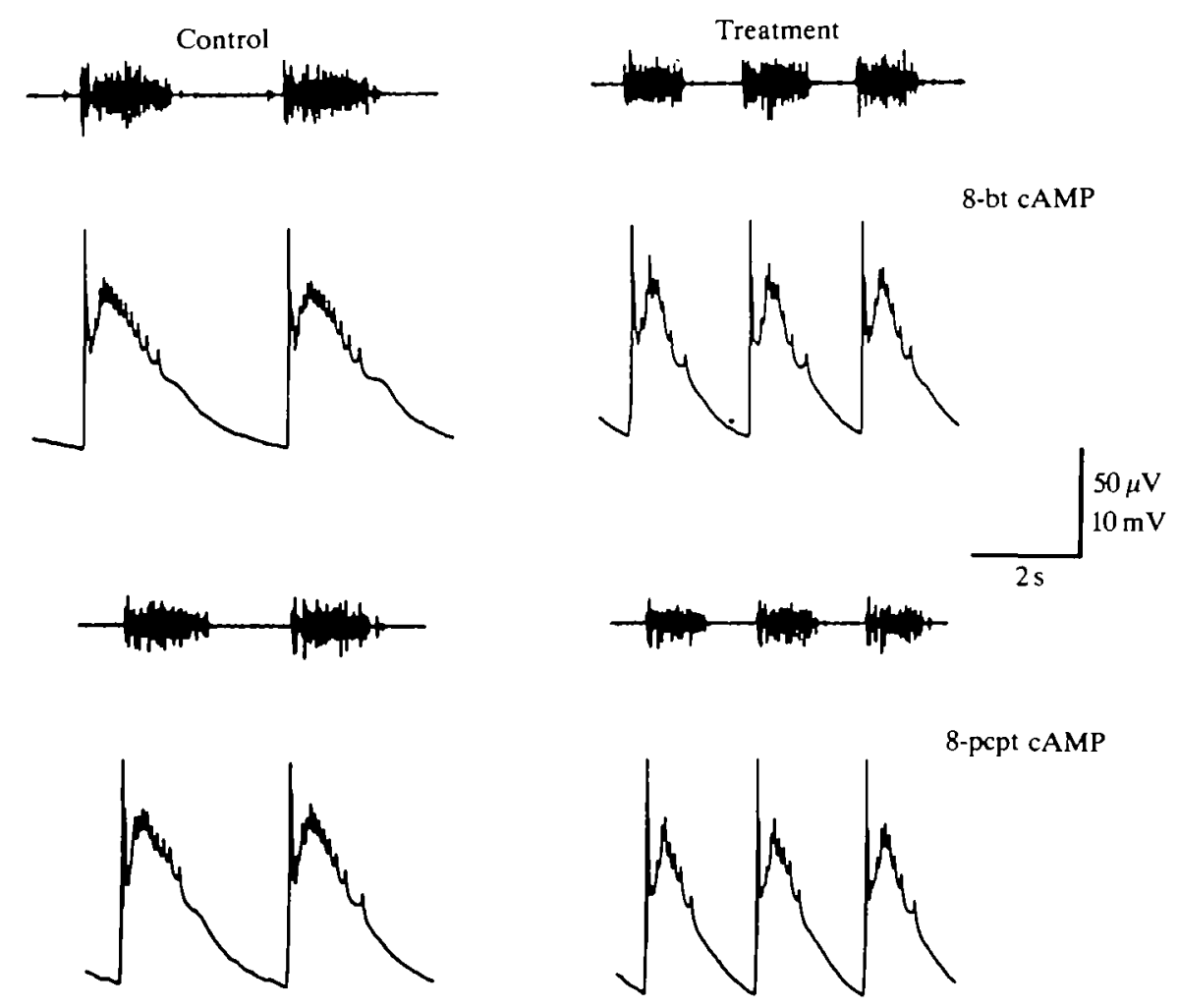

Fig. 5. Cyclic nucleotide analogues produced amine-like effects on the Limulus cardiac ganglion. At $10^{-3} \mathrm{moll}^{-1}$, 8-benzylthio cyclic AMP (8-bt cAMP) and 8-parachloro phenylthio cyclic AMP (8-pcpt cAMP) increased cardiac ganglion burst rate (top record in each trace). These agents, like the amines, forskolin and IBMX, decreased follower neurone interburst interval, burst duration and the number of spikes per burst (bottom record in each trace). 
Previous studies, using $20-50 \mathrm{mmoll}^{-1} \mathrm{Co}^{2+}$ to isolate follower neurones, indicated that DA hyperpolarizes and OCT depolarizes follower neurones (Augustine and Fetterer, 1985). In the present study, similar effects of these amines $\left(10^{-5} \mathrm{moll}^{-1}\right)$ were observed in follower neurones of cardiac ganglia treated with $\mathrm{Mn}^{2+}$ (Fig. 6). Forskolin, at $5 \times 10^{-6} \mathrm{moll}^{-1}$, depolarized these cells by $7.4 \pm 0.7 \mathrm{mV}(N=8)$ and IBMX, at $10^{-3} \mathrm{moll}^{-1}$, produced a $6.0 \pm 1.1 \mathrm{mV}$ depolarization $(N=9)$.

In some $\mathrm{Mn}^{2+}$-treated preparations, infrequent ( $\leqslant 1$ per $10 \mathrm{~min}$ ) and transient 1-2 $\mathrm{mV}$ changes in follower neurone resting potential were observed. In all experiments utilizing $\mathrm{Mn}^{2+}$, OCT, DA, forskolin and IBMX elicited transient
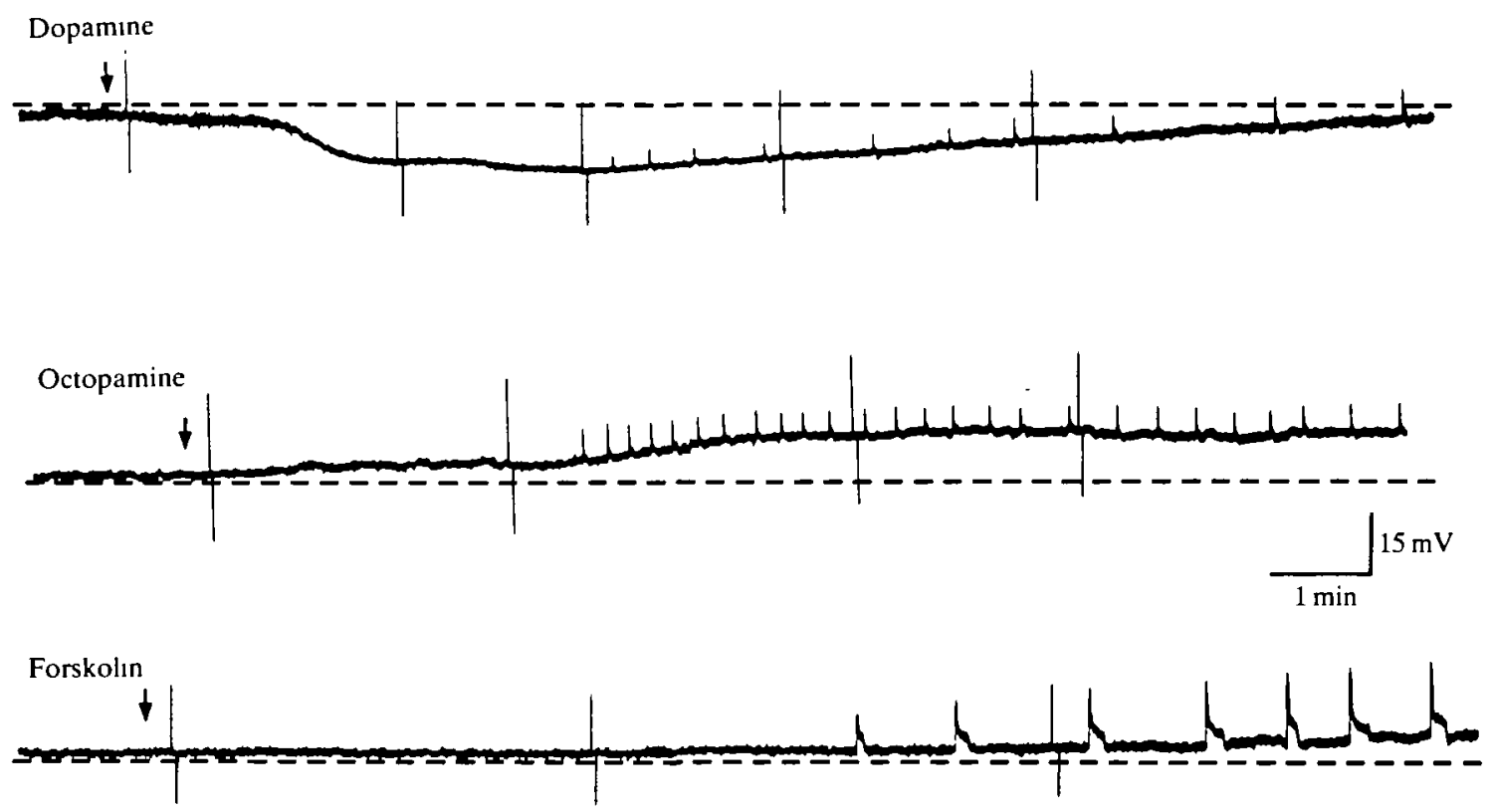

IBMX

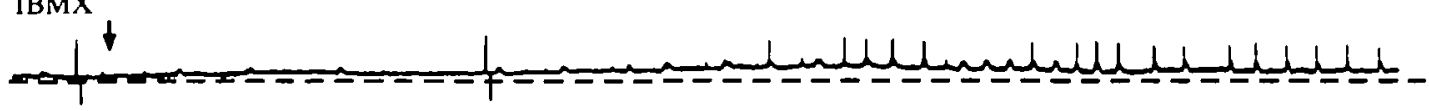

Fig. 6. Effects of dopamine $\left(10^{-5} \mathrm{moll}^{-1}\right)$, octopamine $\left(10^{-5} \mathrm{moll}^{-1}\right)$, forskolin $\left(5 \times 10^{-6} \mathrm{moll}^{-1}\right)$ and IBMX $\left(10^{-3} \mathrm{moll}^{-1}\right)$ on follower neurones in Limulus cardiac ganglia pretreated with $30 \mathrm{mmoll}^{-1}$ manganese to inhibit synaptic input from pacemaker neurones. While dopamine hyperpolarized follower neurones, octopamine, forskolin and IBMX all gradually depolarized these cells by several millivolts. Input resistance was decreased slightly during exposure to dopamine, as shown by a smaller response to current injection. The other compounds did not influence apparent input resistance. These agents also elicited or enhanced burst-like depolarizations of follower cells. 
depolarizations of follower neurones, or increased the frequency and magnitude of spontaneous activity (Fig. 6). These depolarizations resembled follower neurone bursts to some extent, since they consisted of a sharp depolarizing phase followed by a slowly decaying plateau potential, upon which attenuated action potentials were occasionally observed. Like the gradual depolarization produced by OCT, forskolin and IBMX, this effect persisted well into the wash period. No spontaneous or induced burst-like potentials were observed in follower neurones when $30-40 \mathrm{mmoll}^{-1}$ cobalt was used, although OCT, forskolin and IBMX gradually depolarized follower neurones under these conditions.

\section{Effects of forskolin and IBMX on cardiac neuromuscular transmission}

The amplitude of unitary, excitatory junction potentials (EJPs) evoked in cardiac muscle fibres was increased by the application of $5 \times 10^{-6} \mathrm{moll}^{-1}$ forskolin or $10^{-3} \mathrm{~mol}^{-1}$ IBMX (Fig. 7). The increase in EJP amplitude produced by either agent was slow in onset and in decay, similar to the effect of DA or OCT on this preparation (Watson et al. 1985; J. R. Groome, unpublished observations). Forskolin caused a greater and longer-lasting increase $(180.2 \pm 5.9 \%$ control, $N=11)$ than did IBMX $(131.2 \pm 7.0 \%$ control, $N=14)$. Like the amines, these agents did not alter the apparent input resistance or the resting potential of cardiac muscle fibres.

\section{Discussion}

The pharmacological and biochemical data of this study suggest that cyclic AMP plays an important role in several excitatory actions of OCT and catecholamines on the Limulus cardiac ganglion. Amine-induced alterations of cardiac ganglion burst rate and cyclic nucleotide content suggest that cyclic AMP underlies the positive chronotropic effect of these amines on the neurogenic Limulus heart. Furthermore, the excitatory actions of amines on follower neurone somata or their terminals are mimicked by pharmacological elevation of cyclic AMP level. Apparently, this second messenger is involved in multiple actions of amines on neurones of the Limulus cardiac ganglion.

\section{Roles of cyclic AMP and cyclic GMP in amine modulation of burst rate in the Limulus cardiac ganglion}

Our results indicate that the excitatory chronotropic actions of OCT, EPI, DA and NE on the Limulus cardiac ganglion result from increased levels of cardiac ganglion cyclic AMP. The magnitude of the excitatory effect of these amines on burst frequency in the cardiac ganglion was closely correlated with their effect on cyclic AMP metabolism within this tissue. A similar correlation between the magnitude of these effects was observed for the pharmacological agents forskolin and IBMX.

Octopamine and the catecholamines increase cardiac ganglion burst rate in Limulus by increasing the frequency of pacemaker neurone action potentials 

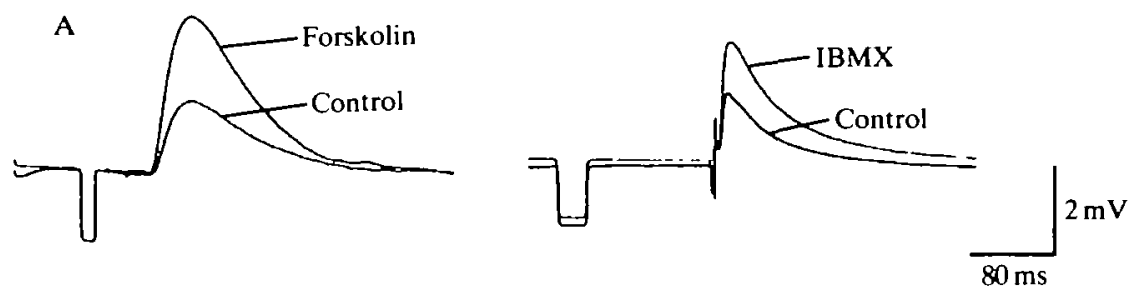

B

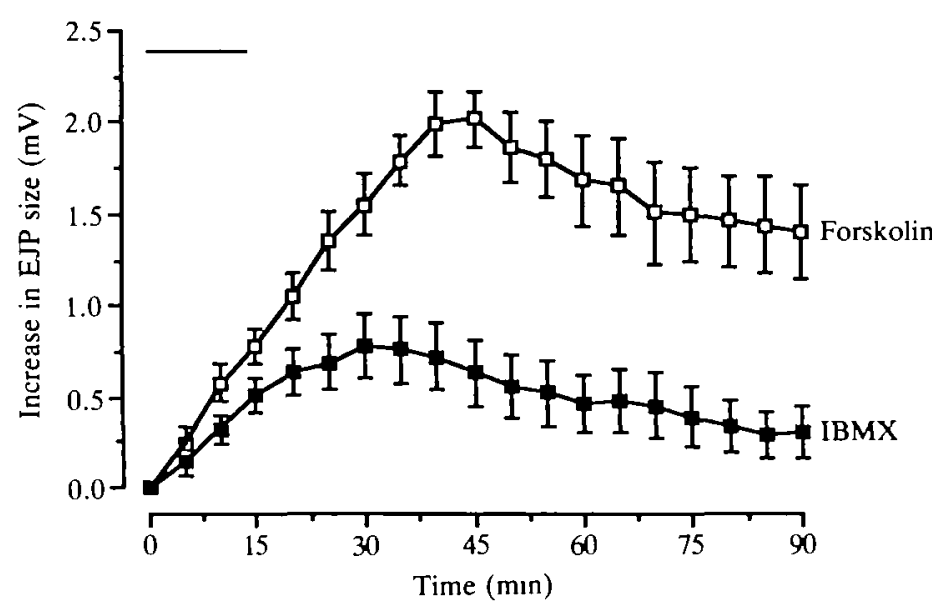

Fig. 7. Forskolin and IBMX, like the amines, enhanced cardiac neuromuscular transmission without altering resting potential or apparent input resistance of cardiac muscle fibres. (A) Record of excitatory junction potentials (EJPs) evoked in cardiac muscle fibres. The average of 30 sweeps is shown before addition of $5 \times 10^{-6} \mathrm{moll}^{-1}$ forskolin or $10^{-3} \mathrm{moll}^{-1}$ IBMX and during the peak response to these compounds. Apparent input resistance was measured by the response of cardiac muscle fibres to a hyperpolarizing current pulse prior to elicitation of the EJP. (B) Time course of the increase in EJP size after addition (solid line) of forskolin $\left(5 \times 10^{-6} \mathrm{moll}^{-1}\right)$ or IBMX $\left(10^{-3} \mathrm{moll}^{-1}\right)$ to the preparation. Each point represents the mean value ( \pm S.E.M.) of 11-14 experiments.

(Augustine and Fetterer, 1985). Burst frequency is increased when amines are applied by pressure ejection onto pacemaker cells, but similar application of amines onto follower cells has no effect. Although the chronotropic effect of these amines is probably the result of elevated pacemaker neurone cyclic AMP level, it has not been possible to measure the relative increases in follower and pacemaker cell cyclic AMP after exposure to amines. Further studies are needed to clarify the intracellular events in these neurones during aminergic modulation.

While the onset kinetics of amine-induced increases in cardiac ganglion burst rate or cyclic AMP level were very similar, the time course of their decay differed ponsiderably. After removal of amine from the cardiac ganglion, levels of cyclic AMP declined to control levels within $10 \mathrm{~min}$, while cardiac ganglion burst rate 
remained elevated for over $60 \mathrm{~min}$. The most likely explanation for this discrepancy is that biochemical processes initiated by cyclic AMP in the Limulus cardiac ganglion (protein kinase activation and substrate phosphorylation) persist after cyclic AMP levels have dropped (for reviews, see Greengard, 1976; Levitan et al. 1983).

It is possible that some other second messenger, in addition to cyclic AMP, might be involved in the chronotropic excitation produced by OCT and the catecholamines. However, available data suggest that two other well-known systems, at least, are not involved. Cyclic GMP does not appear to be involved in excitatory actions of amines on the Limulus cardiac ganglion. None of the amines altered levels of cardiac ganglion cyclic GMP, nor did forskolin. While IBMX was extremely potent in its capacity to elevate cyclic GMP levels in this tissue, the magnitude of its chronotropic effect was quite similar to that produced by agents which exclusively increased levels of cyclic AMP. Phorbol esters, which mimic the second messenger diacylglycerol of the phosphatidylinositol (PI) system (Castagna et al. 1982), do not increase heart rate or cardiac ganglion cyclic AMP level in Limulus (Groome, 1988; Groome and Watson, 1989).

Dopamine, but not OCT, often produces a transient inhibition of cardiac ganglion burst rate prior to its excitatory effect (Augustine $e t$ al. 1982). This effect does not appear to be a consequence of altered cyclic nucleotide metabolism in the Limulus cardiac ganglion. Cyclic GMP levels are unaltered by this amine at any time from $30 \mathrm{~s}$ to $10 \mathrm{~min}$ of incubation (DA produces inhibition within $2 \mathrm{~min}$ of application, Augustine and Fetterer, 1985). Additionally, IBMX, which does increase cardiac ganglion cyclic GMP level, does not produce inhibition. While cardiac ganglion cyclic AMP levels are increased by DA within $2 \mathrm{~min}$, the ratio of its pharmacological to its biochemical effects during this period are very similar to those of OCT, which does not produce inhibition. These results suggest that cyclic AMP is involved solely in the excitatory actions of either DA or OCT.

Octopamine and the catecholamines typically produce excitatory chronotropic effects on the neurogenic hearts of arthropods (Grega and Sherman, 1975; Battelle and Kravitz, 1978; Florey and Rathmayer, 1978; Augustine et al. 1982; Miller et al. 1984), although OCT does inhibit the burst rate of the Portunus cardiac ganglion (Benson, 1984). Octopamine-induced increases in cyclic AMP level may underlie the excitatory effect of this amine on the lobster heartbeat (Battelle and Kravitz, 1978). A peptide factor isolated from crustacean neurohaemal organs increases burst rate and cyclic AMP level in lobster cardiac ganglia (Lemos and Berlind, 1981) and Limulus cardiac ganglion cyclic AMP is increased by an FMRFamidelike cardioacceleratory factor partially purified from the Limulus CNS (Groome, 1988). Finally, several amines and the peptides $\mathrm{SCP}_{\mathrm{B}}$ and FMRFamide produce excitation of heart rate and increase tissue levels of cyclic AMP in molluscs (Higgins et al. 1978; Drummond et al. 1985; Lloyd et al. 1985). Thus, it may be that both amines and peptides utilize a common second messenger, cyclic AMP, to produce increases in heart rate in many invertebrates, including molluscs, crustaceans and the chelicerate Limulus. 


\section{Role of cyclic AMP in amine actions on follower neurones}

Cyclic AMP appears to be involved in some, but not all, of the direct actions of amines on follower neurones. The depolarizing action of OCT on pharmacologically isolated follower cells may involve cyclic AMP, since depolarization was elicited by adenylate cyclase activation or by phosphodiesterase inhibition. We did not observe a change in apparent input resistance associated with this depolarization. A conductance change might not be detectable by our technique if it occurred at some site distant from the recording electrode. The mechanism by which DA hyperpolarizes follower neurones is uncertain, but it appears to involve a rapid change in conductance (Augustine and Fetterer, 1985) and our results suggest that cyclic nucleotides are not involved.

Increases in cardiac ganglion burst rate and cyclic AMP levels were associated with several changes in the burst activity of follower neurones. These effects (decreased interburst interval, burst duration, and number of action potentials per burst) are more likely to be a consequence of increased pacemaker firing frequency than of direct action on follower cells themselves. Local application of $\mathrm{DA}$ onto pacemaker neurones produces these characteristic follower cell responses (Augustine and Fetterer, 1985). Further, it is possible to entrain the burst rate of isolated cardiac ganglia with rhythmic electrical stimulation (Watson and Groome, 1989). When burst rate is increased in the absence of amines, by increasing the rate of electrical stimulation, changes in follower neurone burst activity similar to those elicited by amines or forskolin are observed. These findings suggest that cyclic AMP may be only indirectly responsible, by increasing burst rate, for many of the changes in follower neurone burst activity observed during application of amines.

\section{Role of cyclic AMP in amine enhancement of cardiac neuromuscular transmission}

Amines enhance cardiac neuromuscular transmission by their presynaptic actions on follower neurones (Watson and Hoshi, 1981; Watson et al. 1985). Forskolin and IBMX, like the amines, increased the amplitude of EJPs without altering the apparent input resistance or membrane potential of Limulus cardiac muscle fibres. Therefore, cyclic AMP elevation in follower cells or their terminals may be the mechanism by which amines enhance neuromuscular transmission in Limulus. Cyclic AMP underlies similar excitatory effects of amines on the neuromuscular junction in other invertebrates (Enyeart, 1981; Fujiwara and Kobayashi, 1983; Evans, 1984a).

While cyclic AMP appears to be important in this process, the contributions of other second messenger systems at the Limulus cardiac neuromuscular junction remain uncertain. In lobster claw opener muscle, the facilitatory action of serotonin at the neuromuscular junction is mediated in part by cyclic AMP (Goy and Kravitz, 1989) and in part by some other (unidentified) second messenger. A similar action of serotonin at the neuromuscular junction in crayfish dactyl opener 
muscle appears to involve both the cyclic AMP and PI systems (Dixon and Atwood, 1989). In Limulus, phorbol esters appear to increase the amplitude of evoked EJPs in cardiac muscle, but it is uncertain at present if this result is due to a presynaptic phenomenon or is a secondary effect of increased cardiac muscle fibre excitability (J. R. Groome, unpublished observations). Further studies are needed to clarify the role of cyclic nucleotides and other second messengers in these systems.

\section{Possible involvement of cyclic AMP in pacemaker-follower synaptic efficacy}

The observation that, in some preparations, follower cells exposed to $30 \mathrm{mmoll}^{-1} \mathrm{Mn}^{2+}$ exhibited (albeit very infrequently) transient depolarizations suggests that $\mathrm{Mn}^{2+}$ is not quite as effective as $\mathrm{Co}^{2+}$ in blocking calcium-dependent synaptic transmission between pacemaker and follower neurones of the Limulus cardiac ganglion. Therefore, during $\mathrm{Mn}^{2+}$ treatment pacemaker neurones may occasionally release a quantity of transmitter, producing potential changes in follower neurones.

Forskolin, IBMX and the amines produced increases in the size, duration and frequency of these small burst-like potentials. These observations raise the possibility that amines, via a cyclic-AMP-dependent mechanism, enhance synaptic efficacy between pacemaker and follower neurones. Amines might increase cyclic AMP level in pacemaker neurone terminals, leading to an increase in the amount of transmitter released per pacemaker action potential. Such an action would enhance follower cell bursts, initiated by summation of depolarizing input from several pacemaker cells during each heartbeat cycle (Palese et al. 1970; Lang, 1971).

\section{Phosphodiesterase activity in the Limulus cardiac ganglion}

The Limulus cardiac ganglion appears to have a highly active cyclic-AMPdependent phosphodiesterase. Removal of OCT or DA from the bath resulted in a rapid drop in levels of cardiac ganglion cyclic AMP. Additionally, the phosphodiesterase inhibitor IBMX significantly potentiated the cyclic-AMP-elevating action of OCT and DA on this tissue. The biochemical effect of IBMX in the cardiac ganglion is consistent with an earlier finding in which IBMX potentiated the chronotropic effect of threshold doses of these amines on the Limulus heartbeat (Groome and Watson, 1987). The relative activities of the phosphodiesterase in the Limulus cardiac ganglion (highly active) and myocardium (low activity) may limit amine-induced increases in heart rate, resulting in longer-lasting enhancement of heart contraction strength (Groome and Watson, 1989).

While IBMX significantly increased cardiac ganglion burst rate and cyclic AMP levels, another phosphodiesterase inhibitor, RO-20-1724, did not. This agent is also ineffective on Limulus cardiac muscle (Groome and Watson, 1989). These results may reflect a considerable difference in the capacities of the RO compound and IBMX to penetrate the Limulus cardiac ganglion or a marked difference in potency in this system. Other tissues, such as the locust extensor tibiae muscle, 
exhibit such a differential sensitivity to certain types of phosphodiesterase inhibitors (Evans, 1984b).

Taken together with previous findings on the role of cyclic AMP in amine modulation of cardiac muscle contractility (Groome and Watson, 1989), these studies indicate that cyclic AMP is an important second messenger in the excitatory actions of amines at multiple loci within the neurogenic Limulus heart. However, the intracellular substrates within cardiac ganglion neurones or cardiac muscle fibres modulated by cyclic AMP are still unknown. The determination of the biochemical events following amine-induced increases of cyclic AMP levels in neurones and muscle fibres of the Limulus heart represents an interesting challenge, as does the future study of the relative contributions of other second messengers in this system.

We would like to thank the faculty and staff at the University of Washington marine station at Friday Harbor on San Juan Island, Washington, where preliminary experiments on the Limulus cardiac neuromuscular junction were performed. We would also like to thank Dr John Sasner for the use of his digital oscilloscope, which allowed us to complete these experiments at the University of New Hampshire. We appreciate the comments of Drs Irwin Levitan, John Sasner, Ed Tillinghast and Gordon Wyse on earlier drafts of this manuscript. We also thank Bridget Mansfield, Richard Nero and Al Vetrovs for assistance with horseshoe crab collection. This work was supported by grants from the following sources: UNH CURF S-277 and S-355 to JRG, NIH 5-R01-NS19053-03, NH Heart Association PGM: Fa440A and 86167 to WHW, and NSF DMB 8517284 to the UNH Marine Biomedical Group. It is based on a dissertation submitted by JRG in partial fulfilment of the requirements for the degree of Doctor of Philosophy at the University of New Hampshire.

\section{References}

Augustine, G. J. ANd Fetterer, R. H. (1985). Neurohormonal modulation of the Limulus heart: amine actions on cardiac neurones. J. exp. Biol. 118, 53-69.

Augustine, G. J., Fetterer, R. and Watson, W. H. (1982). Amine modulation of the neurogenic Limulus heart. J. Neurobiol. 13 (1), 61-74.

Battelle, B.-A. AND Kravitz, E. A. (1978). Targets of octopamine action in the lobster: cyclic nucleotide changes and physiological effects in hemolymph, heart and exoskeletal muscle. J. Pharmac. exp. Ther. 205, 438-448.

Benson, J. A. (1984). Octopamine alters rhythmic activity in the isolated cardiac ganglion of the crab, Portunus sanguinolentus. Neurosci. Lett. 44, 59-64.

CARLSON, A. J. (1904). The nervous origin of the heartbeat in Limulus and the nervous nature of co-ordination of conduction in the heart. Am. J. Physiol. 12, 67-74.

Castagna, M., Takal, Y., Kaibuchi, K., Sano, K., Kikkawa, U. and Nishizuka, Y. (1982). Direct activation of calcium-activated, phospholipid-dependent protein kinase by tumour promoting phorbol esters. J. biol. Chem. 257, 7847-7851.

COOKE, I. M. AND Sullivan, R. E. (1982). Hormones and neurosecretion. In Biology of Crustacea, vol. 3 (ed. H. L. Atwood and D. C. Sandeman), pp. 205-290. New York: Academic Press.

Dixon, D. AND ATwood, H. L. (1989). Conjoint action of phosphatidylinositol and adenylate 
cyclase systems in serotonin-induced facilitation at the crayfish neuromuscular junction. J. Neurophysiol. 62 (6), 1251-1259.

Drummond, G. I., Wernham, S. and LuKowiak, K. (1985). Stimulation of adenylate cyclase in the heart of Aplysia californica by biogenic amines. Comp. Biochem. Physiol. 80 C, 129-133.

Edwards, S. C., Pierce, S. K. and Batelle, B. A. (1979). Hyposmotic stress-induced release of octopamine from isolated cardiac ganglia of Limulus polyphemus. Am. Zool. 19, 859.

ENYEART, J. (1981). Cyclic AMP, 5-HT, and the modulation of transmitter release at the crayfish neuromuscular junction. J. Neurobiol. 12 (5), 505-513.

Evans, P. D. (1984a). A modulatory octopaminergic neurone increases cyclic nucleotide levels in locust skeletal muscle. J. Physiol., Lond. 348, 307-324.

Evans, P. D. (1984b). Studies on the mode of action of octopamine, 5-hydroxytryptamine and proctolin on a myogenic rhythm in the locust. J. exp. Biol. 110, 231-251.

Florey, E. AND Rathmayer, M. (1978). The effects of octopamine and other amines on the heart and on neuromuscular transmission in decapod crustaceans: further evidence for a role as a neurohormone. Comp. Biochem. Physiol. 61 C, 229-237.

FujIWARa, M. AND Kobayashi, M. (1983). Modulation of neuromuscular transmission by serotonin in the molluscan radular muscles: involvement of cyclic nucleotides. Comp. Biochem. Physiol. 75 C, 239-246.

Goy, M. F. AND Kravitz, E. A. (1989). Cyclic AMP only partially mediates the actions of serotonin at lobster neuromuscular junctions. J. Neurosci. 9 (1), 369-373.

Greengard, P. (1976). Possible role for cyclic nucleotides and phosphorylated membrane proteins in postsynaptic actions of neurotransmitters. Nature, Lond. 260, 101-108.

GrEGA, D. S. AND ShERMAN, R. G. (1975). Responsiveness of neurogenic hearts to octopamine. Comp. Biochem. Physiol. 52 C, 5-8.

GroOME, J. R. (1988). Peptide and amine actions on the neurogenic Limulus heart: biochemical mechanisms of modulation. PhD dissertation, University of New Hampshire.

Groome, J. R. AND WATSON, W. H. III (1987). Mechanism for amine modulation of the neurogenic Limulus heart: evidence for involvement of cAMP. J. Neurobiol. 18 (5), 417-431.

GroOme, J. R. AND Watson, W. H. III (1989). Second messenger systems underlying amine and peptide actions on cardiac muscle in the horseshoe crab, Limulus polyphemus. J. exp. Biol. $145,419-437$.

Higgins, W. J., Price, D. A. And Greenberg, M. J. (1978). FMrFamide increases the adenylate cyclase activity and cyclic AMP level of molluscan heart. Eur. J. Pharmac. 48, 425-430.

LANG, F. (1971). Intracellular studies on pacemaker and follower neurons in the cardiac ganglion of Limulus. J. exp. Biol. 63, 33-52.

Lemos, J. R. AND BerLind, A. (1981). Cyclic adenosine monophosphate mediation of peptide neurohormone effects on the lobster cardiac ganglion. J. exp. Biol. 90, 307-326.

Levitan, I. B., Lemos, J. R. and Novak-Hofer, I. (1983). Protein phosphorylation and the regulation of ion channels. Trends Neurosci. 6 (12), 496-499.

Lloyd, P. E., Kupferman, I. ANd Weiss, K. R. (1985). Two endogenous neuropeptides (SCP and $\mathrm{SCP}_{\mathrm{B}}$ ) produce a cAMP-mediated stimulation of cardiac activity in Aplysia. J. comp. Physiol. 156 A, 659-667.

Lowry, O. H., Rosebrough, N. J., Farr, A. L. and Randall, R. J. (1951). Protein measurement with the Folin phenol reagent. J. biol. Chem. 193, 265-275.

Miller, M. W., Benson, J. A. And Berlind, A. (1984). Excitatory effects of dopamine on the cardiac ganglia of the crabs Portunus sanguinolentus and Podophthalamus vigil. J. exp. Biol. 108, 97-118.

O'Connor, E. F., Watson, W. H. AND WySE, G. A. (1982). Identification and localization of catecholamines in the nervous system of Limulus polyphemus. J. Neurobiol. 13 (1), 49-60.

Palese, V. J., Becker, J. L. ANd Pax, R. A. (1970). Cardiac ganglion of Limulus: intracellular activity in the unipolar cells. J. exp. Biol. 53, 411-423.

Seamon, K. B. AND DaLy, J. W. (1981). Forskolin, a unique diterpene activator of adenylate cyclase. J. cycl. Nucleotide Res. 7, 201-224.

Sullivan, R. E. AND Barker, D. L. (1975). Octopamine increases cyclic AMP content of crustacean ganglia and cardiac muscle. Soc. Neurosci. Abstr. 1, 394. 
Watson, W. H. III and Augustine, G. J. (1982). Peptide and amine modulation of the Limulus heart: a simple nervous network and its target tissue. Peptides 3, 485-492.

Watson, W. H. III and Groome, J. R. (1989). Modulation of the Limulus heart. Am. Zool. 29, $1287-1303$.

Watson, W. H. III AND Hoshi, T. (1981). Amines increase the strength of Limulus heart contractions by enhancing neuromuscular transmission. Biol. Bull. mar. biol. Lab., Woods Hole 161, 317.

Watson, W. H. III, Hoshi, T., Colburne, J. and Augustine, G. J. (1985). Neurohormonal modulation of the Limulus heart: amine actions on neuromuscular transmission and cardiac muscle. J. exp. Biol. 118, 71-84. 